\title{
TEMPERATURE MEASUREMENTS IN A RAPID COMPRESSION MACHINE USING ANISOLE PLANAR LASER-INDUCED FLUORESCENCE
}

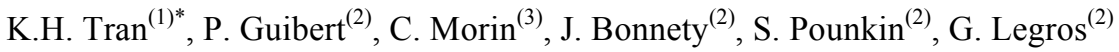 \\ ${ }^{(1)}$ Laboratoire Energétique, Mécanique et Electromagnétisme, Université Paris Ouest, \\ 50 rue de Sèvres, 92410 Ville d'Avray \\ ${ }^{(2)}$ Institut Jean Le Rond d'Alembert - CNRS UMR 7190, Université Pierre et Marie Curie (Paris 6) \\ 2, place de la Gare de Ceinture 78210 Saint-Cyr-l'Ecole France \\ ${ }^{(3)}$ LAMIH CNRS UMR 8201, UVHC, Le Mont Houy, 59313 Valenciennes Cedex 9, France \\ * Corresponding author: khtran@u-paris10.fr
}

\begin{abstract}
Advanced combustion processes induced by self-ignition mechanisms in piston engines, such as Homogeneous Charge Compression Ignition (HCCI), especially need an accurate spatio-temporal temperature information because their phenomenology therefore their performances highly depend on the thermal conditions. The objective of this study is to measure the temperature distribution inside a rapid compression machine (RCM) using anisole planar laser induced fluroescence. The present paper gives a new insight into the interpretation of RCM autoignition data. It also brings useful information for kinetics-related combustion research and combustion modeling. The anisole planar laser-induced fluorescence (PLIF) technique is applied, in order to observe the formation and the evolution of temperature heterogeneities in the combustion chamber prior to the autoignition process. Anisole is used as a novel tracer species, and the fluorescence signal's dependence on parameters, such as temperature, pressure and bath gas composition, is quantified in a high-pressure, high-temperature facility. Calibration of the fluorescence signal is defined under RCM-related temperature and pressure conditions and a protocol is proposed for postprocessing of the PLIF image sequences, allowing the quantitative field temperatures to be determined at successive instants following compression. In order to gain a better understanding of the mixture process, Particle Image Velocimetry (PIV) measurements are analysed under the same conditions. The correlation between thermal and aerodynamic phenomena is determined. The temperature field is found to be non-uniform, with hot and cold centre positions resulting from recirculation inside the chamber, combined with heat transfer effects from the chamber wall.
\end{abstract}

Keywords: temperature measurement, planar laser-induced fluorescence, rapid compression machine, particle image velocimetry, anisole, temperature heterogeneities

\section{Introduction}

The present study describes temperature measurements in a rapid compression machine (RCM) using anisole as tracer for PLIF technique. This device is well suited to the study of combustion processes under similar conditions to those experienced in an IC engine, enabling the measurements of fuel ignition delays and the validation of kinetics mechanisms [1], [2] . It is thus 
essential to characterize the RCM temperature fields, using a non-intrusive optical technique such as PLIF. Clarkson et al. [3] used PLIF to measure temperature fields in an RCM, with an acetone tracer under non-reactive conditions, and with DTBP (di-tert-butyl peroxide) decomposition, which forms acetone under reactive conditions. As their measurements were not calibrated, no quantitative data was reported. These authors observed a spatially non-uniform temperature field following compression, with a cold core. This consequence may affect chemical development and ignition delay measurements. The measurement of temperature distributions in an RCM using acetone PLIF, at different times along compression, was proposed by Mittal and Sung [4] (2006). Thurber et al. [5] inferred temperature fields from the fluorescence signal by accounting for absorption phenomena and temperature effects. In-cylinder temperature imaging was also applied to the study of an IC engine, using toluene fluorescence at a single excitation wavelength and twocolour detection [6] , and using 3-pentanone [7], [8]. Löffler et al. [9] used acetone with the dual excitation wavelength technique, at $308 / 277 \mathrm{~nm}$ and $308 / 248 \mathrm{~nm}$.

Similar approaches have been described in the literature. Strozzi et al. [10] used PLIF to characterize a two-dimensional temperature field in an RCM, with a single-excitation, two-colour detection technique, relying on the temperature dependence of toluene fluorescence established by Koban et al. [11], at atmospheric pressure and for the temperature range 300-950 K. These authors obtained temperature fields that clearly revealed a distorted structure, in particular at the boundary between the hot and cold zones. In-cylinder temperature imaging using a shock tube or spray has also been applied to the study of IC engines. Kaiser et al. [12] studied the LIF imaging of toluene at an excitation wavelength of $248 \mathrm{~nm}$, to determine the spatial fluctuations of gas temperature in an optically accessible engine. These fluctuations are due to wall heat-transfer during the compression stroke in a homogeneous mixture. Löffler et al. [9] presented calibration results from acetone fluorescence signal intensities in nitrogen, air, and an exhaust gas-air mixture, at temperatures ranging from 298 to $748 \mathrm{~K}$ and pressures ranging from 0.02 to $2 \mathrm{MPa}$, using $308 \mathrm{~nm}$ and $248 \mathrm{~nm}$ excitation wavelengths. From this data, inferred from single-shot images, temperature and exhaust gas concentrations in a spark ignition engine were accurately determined. The computed accuracy of the calibration data was $5.6 \%$, and 3.2\% for the signal measured under single wavelength excitation and for the signal ratio, respectively. The uncertainties in the measurements, made with an exhaust gas recirculation / air mixture, were slightly higher, as a consequence of small uncertainties in the mixing ratio: the errors were $6.9 \%$ and $5.1 \%$ for single wavelength excitation, and for the signal ratio, respectively.

Yoo et al. [13] used the PLIF technique to image temperature fields close to the walls of a shock tube. Two types of near-wall flow were considered: the sidewall thermal boundary layer behind an incident shock wave, and the end-wall thermal boundary layer behind a reflected shock wave. These thin layers were imaged at a high spatial resolution $(15 \mu \mathrm{m} / \mathrm{pixel})$, using fused silica walls and near-UV bandpass filters to accurately measure the fluorescence signals with minimal interference from scattering and reflection effects at the wall surfaces. Nitrogen, hydrogen or argon gases were premixed with $1-12 \%$ toluene, with the LIF tracer. The measured pressures and temperatures ranged between 0.01 and 0.8 bar, and 293 and $600 \mathrm{~K}$, respectively. The temperature field measurements were found to be in good agreement with the theoretical values calculated using 2-D laminar boundary layer and 1-D heat diffusion equations, respectively. In addition, PLIF images were taken at various times, behind incident and reflected shock waves, in order to observe the development of the sidewall and end-wall layers, respectively. This demonstrated that this diagnostic strategy can be used to accurately measure temperatures at distances as close as $60 \mu \mathrm{m}$ to the wall. The temperature measurement accuracy within the sidewall boundary layer is approximately $\pm 5 \mathrm{~K}$. Cundy et al. [14] developed a high-speed transient temperature measurement technique using high-speed toluene LIF. They used single wavelength excitation at $266 \mathrm{~nm}$, combined with detection within two spectral regions, yielding a calibrated, temperature-dependent signal ratio at temperatures between 373 and $873 \mathrm{~K}$. These experiments were carried out in a wellstabilized heated nitrogen jet, to avoid signal reduction due to collisional quenching by oxygen. 
Although the sensitivity of the diagnostics suggested that the accuracy should increase with increasing temperature, the fluorescence signal decreased strongly, and the associated noise levels were higher with increasing temperature, such that the error actually increased. The one standard deviation errors were computed as \pm 8 and $\pm 25 \mathrm{~K}$, at $373 \mathrm{~K}$ and $773 \mathrm{~K}$, respectively.

The selection of the tracer is a crucial parameter of the LIF implementation. Among the potential tracers, small aromatic molecules, such as toluene (Luong, Koban, \& Schulz, Novel strategies for imaging temperature distribution using toluene LIF, 2006) and naphthalene (Kaiser \& Long, Quantitative planar laser-induced fluorescence of naphtalenes as fuel tracers, 2005), (Hirasawa, Kaneba, Kamata, Muraoka, \& Nakamura, 2007), are attractive [15] due to their high-fluorescence quantum yield (FQY). However, anisole can be a potential candidate for use as fluorescent tracer for gas-phase imaging diagnostics. Due especially to its high FQY, its large absorption crosssection, and its Stokes shift, anisole can deliver a signal intensity up to 100 times stronger than conventional tracers such as toluene. This makes anisole a novel tracer alternative.

In the present study, quantitative temperature imaging was conducted in an RCM for the first time using the single excitation two-colour detection technique based on anisole fluorescence, including a prior calibration process over the range of experimental conditions met in the RCM.

The experimental facilities and the image processing procedures are first outlined. A selection of 2D temperature fields are then combined with the velocity fields measured inside the combustion chamber to highlight the key role of the hydrodynamic features on the thermal conditions met in a RCM.

\section{Experimental set-up}

\subsection{PLIF Model overview}

The planar laser-induced fluorescence (PLIF) technique is well suited to this type of measurement, due to its sensitivity and ability to provide two-dimensional measurements with a high spatial resolution. The global expression governing the fluorescence signal $\mathrm{S}_{\mathrm{f}}$ depends on terms that quantify the sensitivity of the signal to the pressure, temperature, composition of the gas mixture, optical matching of the absorption cross-section, and fluorescence quantum yield [5]:

$\mathrm{S}_{\mathrm{f}}=\frac{\mathrm{E}}{\mathrm{hc} / \lambda} \eta_{\text {opt }} \mathrm{dV}\left[\frac{\mathrm{XP}}{\mathrm{kT}}\right] \sigma(\lambda, \mathrm{T}) \Phi(\lambda, \mathrm{T}, \mathrm{P}, \mathrm{X})$

where $\mathrm{E}$ is the laser fluence, (hc/ $\lambda)$ is the energy of a photon at the excitation wavelength $\lambda$, $\eta_{\text {opt }}$ is the overall efficiency of the collection optics, $k$ is the Boltzmann constant, and $d_{\mathrm{c}}$ is the collection volume. The terms characterizing the tracer are $\sigma$, its molecular absorption crosssection, and $\Phi$, its fluorescence quantum yield. The tracer mole fraction $\mathrm{X}$, total pressure $\mathrm{P}$, and temperature $\mathrm{T}$ define the experimental thermodynamic conditions.

In the case of a gaseous single phase, as described in the present study, three different LIF-based temperature measurement techniques can be used. The first of these is a single-excitation, single colour detection approach. It requires a homogeneous distribution of a tracer together with the use of a known reference temperature inside the volume probed. The second technique, referred to as single-excitation, two-colour detection, provides with temperature measurements in the case of an inhomogeneous tracer distribution. Finally, the third technique involves the use of a dualexcitation wavelength and two-colour detection. The latter approach allows both concentration and temperature values to be measured. The selection of one of the above techniques is driven by the thermodynamic quantities to be studied, depending on the selected tracer and the specific experimental conditions. In the current study, the single-excitation, two-colour detection technique 
was chosen, since it allows the temperature to be measured in a non-homogeneous seeded flow, provided the pressure is known.

In the general case, the function ratio $\mathrm{S}_{\mathrm{f}}{ }^{*}$ of the fluorescence signals detected in the two spectral bands $\Delta \lambda_{1}$ and $\Delta \lambda_{2}$ is expressed by:

$S_{f}^{*}=\frac{E_{1} \eta_{\text {opt }} \lambda_{1} \int_{\lambda_{\text {low } 1}}^{\lambda_{\text {high } 1}} \sigma_{\text {tracer } 1}\left(\lambda_{1}, T\right) \Phi_{\text {tracer } 1}\left(\lambda_{1}, T, P, X_{i j}\right)}{E_{2} \eta_{\text {opt }} \lambda_{2} \int_{\lambda_{\text {low } 2}}^{\lambda_{\text {high } 2}} \sigma_{\text {tracer } 2}\left(\lambda_{2}, T\right) \Phi_{\text {tracer } 2}\left(\lambda_{2}, T, P, X_{i j}\right)}$

The sensitivity of this ratio depends on the selected spectral wavelength bands $\Delta \lambda_{1}$ and $\Delta \lambda_{2}$, and on the selected temperature measurement technique. In the case of the single-excitation, twocolour detection technique under inhomogeneous conditions, the expression $\mathrm{S}_{\mathrm{f}}{ }^{*}$ can be simplified at a given pressure, as follows:

$S_{f}^{*}=\frac{\eta_{\text {opt } 1} \int_{\lambda_{\text {low } 1}}^{\lambda_{\text {high } 1}} \sigma(\lambda, T) \Phi\left(\lambda, T, P, X_{i j}\right)}{\eta_{\text {opt } 2} \int_{\lambda_{\text {low } 2}}^{\lambda_{\text {high } 2}} \sigma(\lambda, T) \Phi\left(\lambda, T, P, X_{i j}\right)}=\frac{s_{f}^{\Delta \lambda_{1}}(T, P)}{s_{f}^{\Delta \lambda_{2}}(T, P)} \propto \frac{\Phi^{\Delta \lambda_{1}(T)}}{\Phi^{\Delta \lambda_{2}(T)}}=f(T)$

\subsection{Anisole fluorescence calibration set-up}

The fluorescence of a vapour phase anisole $\left(\mathrm{C}_{6} \mathrm{H}_{5} \mathrm{OCH}_{3}\right)$, isooctane $\left(\mathrm{C}_{8} \mathrm{H}_{18}\right)$ blend was investigated in an optically accessible, high pressure, high temperature (HP-HT) chamber (cf. Figure 1), over temperature and pressure ranges of 473-823 $\mathrm{K}$ and $0.2-4 \mathrm{MPa}$, respectively, using a $266 \mathrm{~nm}$ excitation wavelength.

The HP-HT chamber is a cylinder (height $\mathrm{H}=200 \mathrm{~mm}$, external diameter $\varnothing_{\mathrm{ext}}=170 \mathrm{~mm}$, internal diameter $\varnothing_{\text {int }}=70 \mathrm{~mm}$, inner volume $V_{\text {in }}=7.6969 \times 10^{-4} \mathrm{~m}^{3}$ ), heated and maintained at constant temperature by eight $230 \mathrm{~W}$ electrical resistances. A system comprising three thermocouples (accuracy: $\pm 2.3 \mathrm{~K}$ ) located inside the cell allows the temperature to be regulated, and ensures the cell temperature homogeneity. The maximum operating pressure and temperature of the HP-HT chamber are $5 \mathrm{MPa}$ and $873 \mathrm{~K}$, respectively. $1 \mathrm{~mL}$ (accuracy: $\pm 1 \%$ ) of a liquid fuel/tracer mixture is injected into the chamber, via a syringe / capillary tube system, and is then vaporized by means of a vacuum pump as the (temperature-dependent) tracer vapour pressure is reached (anisole vapour pressure of $1360 \mathrm{~Pa}$ at $293 \mathrm{~K}$ ). The experimental chamber is pressurized with different bath gases (Ar, $\mathrm{N}_{2}, \mathrm{CO}_{2}$, air and gas mixtures) via the admission circuit, which is equipped with pressure sensors (accuracy $\pm 1 \%$ ) and valves.
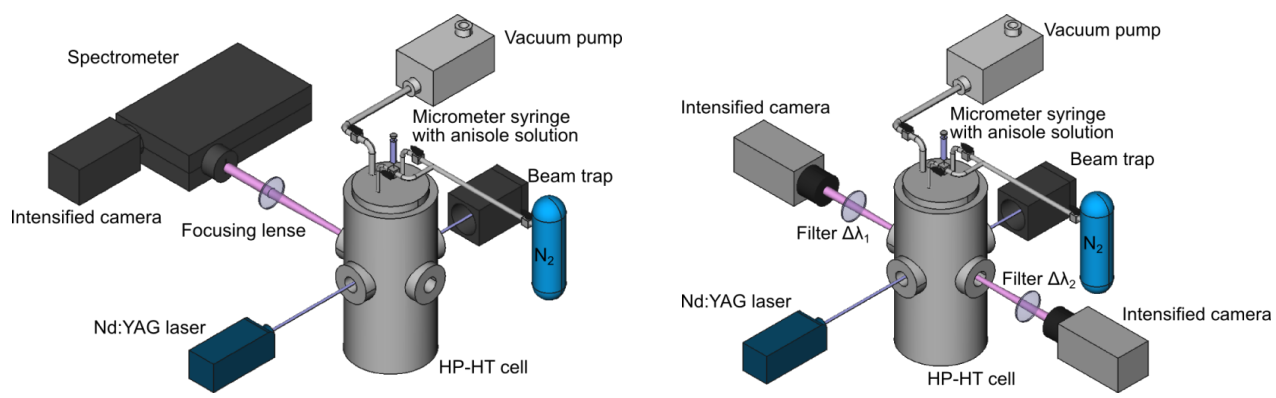

Figure 1: High pressure, high temperature chamber and optical assembly for spectrometer or 2 cameras setup

The optical system comprises a frequency-quadrupled, pulsed Nd:Yag laser $(266 \mathrm{~nm}, 90 \mathrm{~mJ} / \mathrm{pulse}$ at $10 \mathrm{~Hz}$ ) for the fluorescence measurements. The laser beam is not focused, and has a diameter of $10 \mathrm{~mm}$ diameter and a pulse duration of $9 \mathrm{~ns}$. The fluctuations in laser pulse duration are 3-4 ns, with an energy stability of $\pm 8 \%$. The laser beam passes through the cell and is collected by a beam trap and a flux-meter, allowing the time-dependent fluctuations in laser energy and intensity to be determined. The fluorescence signal is collected at a $90^{\circ}$ angle with respect to the incident beam, 
by a spectrometer (focal length: $500 \mathrm{~mm}$, entrance slit width: $500 \mu \mathrm{m}$, diffraction grating: 150 grooves per $\mathrm{mm}$, providing a resolution of $350 \mathrm{~nm}$ ), equipped with an ICCD camera (1024 x 256 pixels $^{2}, 16$ bytes of dynamic range, $100 \mathrm{~ns}$ exposure time) and a UV lens (focal length $=78 \mathrm{~mm}, f$ ratio $=3.8$ and spectral resolution from 230 to $800 \mathrm{~nm})$. Bandpass filters $\left(\Delta \lambda_{1}=386 \pm 11.5 \mathrm{~nm}\right.$ and $\Delta \lambda_{2}=292 \pm 13.5 \mathrm{~nm}$ ) are located in front of the measurement devices in order to calibrate the LIF temperature measurement. The laser intensity and pulse frequency are adjusted to $90 \mathrm{~mJ} / \mathrm{pulse}$ and $10 \mathrm{~Hz}$, in order to avoid saturation, and to remain within the fluorescence linearity regime. The fluorescence tracer concentration is adjusted to $360 \mu \mathrm{l}$ of $1 \%$ anisole in an isooctane solution, corresponding to $2.5810^{16}$ molecule. $\mathrm{cm}^{-3}$ of anisole. This concentration makes re-absorption and self-quenching phenomena negligible.

\subsection{Temperature measurement set-up}

An experimental investigation of the turbulence effect on the combustion propagation in a rapid compression machine has been previously conducted in a RCM [19]. This machine can be separated into four main modules: the hydraulic system, a single piston moving inside a precompression chamber (diameter: $91.5 \mathrm{~mm}$ ), the combustion chamber (diameter: $40 \mathrm{~mm}$, height: 40 $\mathrm{mm}$ ), and the acquisition and control system. Test gas mixtures are loaded into the precompression chamber, and then heated and maintained at $373 \mathrm{~K}$ by three resistors. The entire fast compression process is powered by the hydraulic system, which especially controls the final position of the piston and ensures that it is held without any rebound. The compression ratio is equal to 15 , and the compression time is $29 \mathrm{~ms}$. The stroke can be varied between 150 and 160 $\mathrm{mm}$, and the piston can reach a velocity of $8 \mathrm{~m} . \mathrm{s}^{-1}$. The wall of the cylindrical combustion chamber is made of quartz glass, allowing extensive optical access. The optical system shown in Figure 2 comprises a frequency-quadrupled, pulsed Nd:YAG laser $\left(266 \mathrm{~nm}, 110 \mathrm{~mW}, 7.6 \mathrm{~mW} / \mathrm{mm}^{2}\right)$. In the case of PLIF measurements in the RCM, two intensified ICCD cameras (with UV objectives and two bandpass filters centred at $292 \mathrm{~nm}$ and $386 \mathrm{~nm}$ ), aligned perpendicularly to the laser beam (48 $\mathrm{mm}$ height, $0.2 \mathrm{~mm}$ thickness), are used to collect the fluorescence images. A computer connected to a delay generator is used to synchronize the laser pulse, the exposure of the ICCD cameras, the beginning of the compression cycle, and the image acquisition system.

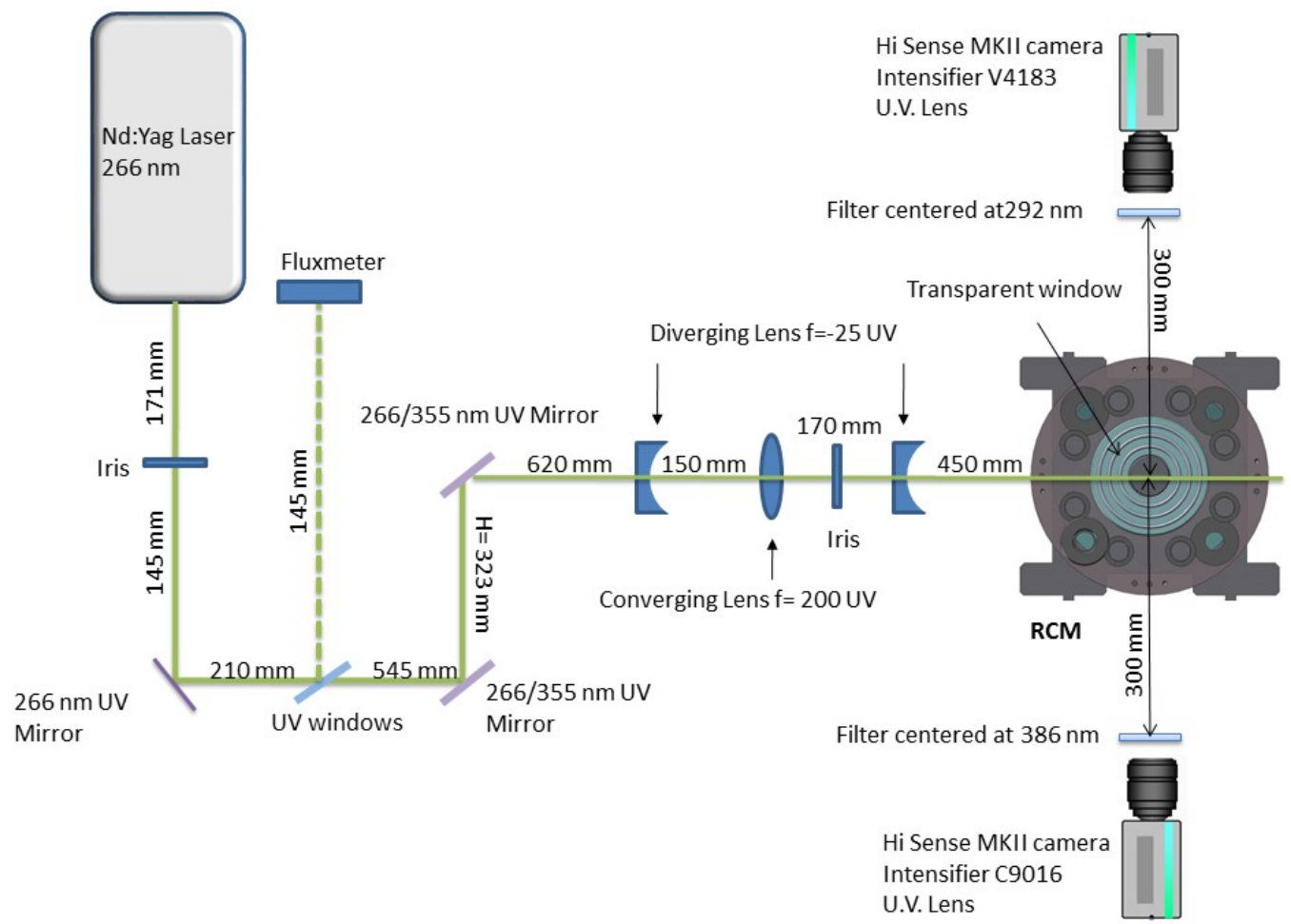


Figure 2: Top view of the optical system for PLIF temperature measurements in the RCM.

Different bath gases are chosen in order to adjust the thermodynamic conditions at the end of compression : argon (Ar) and nitrogen $\left(\mathrm{N}_{2}\right)$ as inert gases, and carbon dioxide $\left(\mathrm{CO}_{2}\right)$ as a gas representing the exhaust gases recirculation in IC engines.

Before compression, the mixture's temperature and pressure are $363 \mathrm{~K}$ and $0.35 \mathrm{bar}$, respectively. In order to characterize the temperature fields inside the RCM just before self-ignition, it was chosen to work with inert gases. The experimental conditions are equivalent to a reactive mixture (n-heptane $\mathrm{C}_{7} \mathrm{H}_{16}$, iso-octane $\mathrm{C}_{8} \mathrm{H}_{18}$, or hydrogen $\mathrm{H}_{2}$ in air), in terms of pressure at the compression end, temporal variations of the pressure, and specific heat capacity. The experimental conditions are summarized in Table 1. As shown in Figure 3, there are only small differences in pressure variation for the two types of mixture (inert and reactive), up to the time of auto-ignition. Temperature measurements are made at top dead centre (TDC), then at 10, 17, 25, 30 and $40 \mathrm{~ms}$ following TDC, as indicated by the red bars in Figure 3.

\begin{tabular}{|c|c|c|c|c|c|c|}
\hline \multirow[t]{2}{*}{ Compound } & \multicolumn{2}{|c|}{$\begin{array}{l}\text { Case 1 : Molar concentration } \\
\qquad 180 \mathrm{~mol} / \mathrm{m}^{3}\end{array}$} & \multicolumn{2}{|c|}{$\begin{array}{c}\text { Case } 2: \text { Molar concentration } \\
160 \mathrm{~mol} / \mathrm{m}^{3}\end{array}$} & \multicolumn{2}{|c|}{$\begin{array}{c}\text { Case } 3: \text { Molar concentration } \\
160 \mathrm{~mol} / \mathrm{m}^{3}\end{array}$} \\
\hline & $\begin{array}{l}\text { Molar } \\
\text { fraction of } \\
\text { reactive } \\
\text { mixture } \\
(\%)\end{array}$ & $\begin{array}{c}\text { Molar fraction } \\
\text { of equivalent } \\
\text { inert mixture } \\
(\%)\end{array}$ & $\begin{array}{c}\text { Molar } \\
\text { fraction of } \\
\text { reactive } \\
\text { mixture }(\%)\end{array}$ & $\begin{array}{c}\text { Molar fraction } \\
\text { of equivalent } \\
\text { inert mixture } \\
(\%)\end{array}$ & $\begin{array}{c}\text { Molar } \\
\text { fraction of } \\
\text { reactive } \\
\text { mixture }(\%)\end{array}$ & $\begin{array}{c}\text { Molar fraction } \\
\text { of equivalent } \\
\text { inert mixture } \\
(\%)\end{array}$ \\
\hline $\mathrm{C}_{8} \mathrm{H}_{18}$ & 0 & 0 & $9.6210^{-3}$ & 0 & 0 & 0 \\
\hline $\mathrm{C}_{7} \mathrm{H}_{16}$ & $1.4210^{-2}$ & 0 & 0 & 0 & 0 & 0 \\
\hline $\mathrm{H}_{2}$ & 0 & 0 & 0 & 0 & $9.3310^{-2}$ & 0 \\
\hline $\mathrm{O}_{2}$ & $1.9610^{-1}$ & 0 & $2.0010^{-1}$ & 0 & $1.1710^{-1}$ & 0 \\
\hline $\mathrm{N}_{2}$ & $2.3710^{-1}$ & $4.2910^{-1}$ & $1.1110^{-1}$ & $2.8910^{-1}$ & $2.3710^{-1}$ & $6.2810^{-2}$ \\
\hline $\mathrm{Ar}$ & $7.9010^{-2}$ & $1.3410^{-1}$ & $6.0010^{-1}$ & $6.9210^{-1}$ & $4.7410^{-1}$ & $9.1610^{-1}$ \\
\hline $\mathrm{CO}_{2}$ & $4.7410^{-1}$ & $4.1910^{-1}$ & $7.9010^{-2}$ & $1.0010^{-3}$ & $7.9010^{-2}$ & $1.0010^{-3}$ \\
\hline $\mathrm{C}_{6} \mathrm{H}_{5} \mathrm{OCH}_{3}$ & 0 & $1.8110^{-2}$ & 0 & $1.8110^{-2}$ & 0 & $1.8110^{-2}$ \\
\hline
\end{tabular}

Table 1: Molar fractions of reactive mixtures and their equivalent inert mixtures for temperature measurements using anisole $\left(\mathrm{C}_{6} \mathrm{H}_{5} \mathrm{OCH}_{3}\right)$ PLIF in an RCM

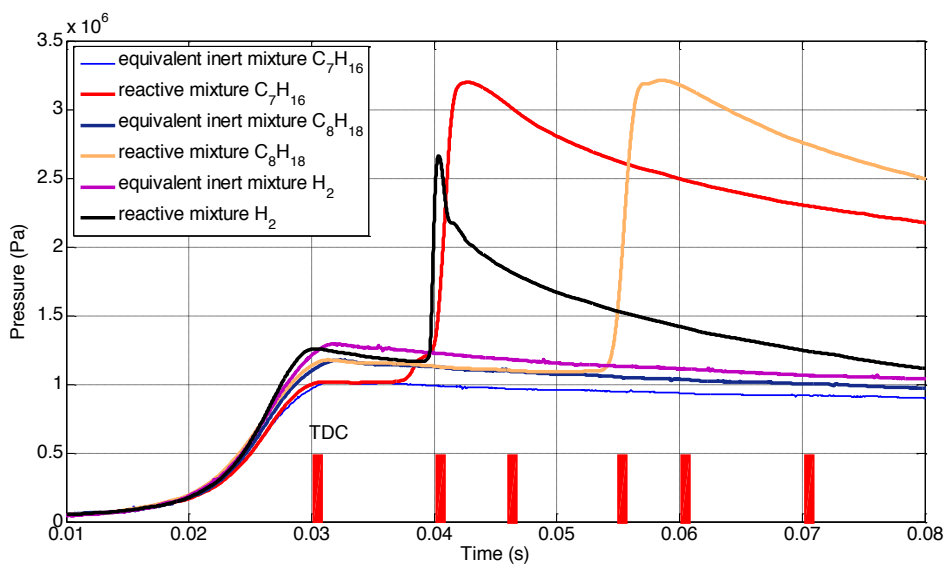

Figure 3: Pressure variations in the RCM combustion chamber for reactive and inert mixtures. The red bars indicate the times of temperature field measurements. 


\section{Results}

\subsection{Calibration of the single excitation two-colour detection technique}

Faust et al. [20] [21] compared the photo-physical properties of toluene, naphthalene, and anisole in terms of temperature, pressure, and bath gas composition dependencies of fluorescence spectra and lifetimes. These authors showed that, with $266 \mathrm{~nm}$ excitation the fluorescence spectrum of anisole at room temperature is red-shifted by $10-15 \mathrm{~nm}$ with respect to that of toluene. This allows the Rayleigh elastically scattered laser light to be discriminated from the fluorescence signal. As compared to the toluene characteristics, anisole exhibits a FQY that is $63 \%$ larger and an absorption cross section about 50 times higher. These features lead to significantly improve the fluorescence signal magnitude under identical conditions.

Naphthalene can be used as an alternative to toluene [22]. However naphtalene is hampered by three factors, i.e., its very weak vapour pressure $(0.024 \mathrm{mbar}$ at $293 \mathrm{~K})$ leading to low concentration in the gas-phase, therefore low LIF signal intensities at low temperature, its solid state at room temperature leading to a re-condensation at high pressure, and its carcinogenic properties restricting its application in flow and combustion studies at atmospheric pressure.

Anisole is a cheap, non-toxic, non-carcinogenic liquid with a vapour pressure of $3.6 \mathrm{mbar}$ at room temperature. Actually, Faust and al. suggested that the anisole behaviour is suitable for quantitative imaging diagnostics of temperature and oxygen over a wide range of temperature and pressure.

Anisole was investigated by Tran et al. (Tran, Morin, Kühni, \& Guibert, 2014) as a tracer due to the high sensitivity of the fluorescence signal to temperature, the redshift being an increasing function of temperature. Furthermore, anisole is shown to be soluble in primary fuels at comparable vapour pressures. The calibration curves reported by Tran et al. [23] were obtained from LIF experiments carried out in the HP-HT cell. Different inert bath gases (argon, nitrogen, carbon dioxide, air and mixtures of these gases) were investigated over temperature and pressure ranging from 473 to $823 \mathrm{~K}$, and from 0.2 to $4 \mathrm{MPa}$, respectively. For any given set of temperature and pressure conditions, the fluorescence signals were averaged over 900 emission spectra. Anisole exhibits a fluorescence emission band between 250-600 nm, with a peak centred at $296 \mathrm{~nm}$, as shown in Figure 4. In nitrogen, the fluorescence intensity decreases strongly, by a factor of 50, when the temperature increases from 473 to $823 \mathrm{~K}$ at a pressure of $1.2 \mathrm{MPa}$, due to the highly non-radiative decay rate of its excited state at high temperatures. This observation further supports the selection of anisole as a tracer for LIF temperature measurements within the aforementioned temperature range. Furthermore, as shown in Figure 4, the redshift of $2 \mathrm{~nm}$ per $100 \mathrm{~K}$ observed in the vicinity of the fluorescence peak represents an advantage for the singleexcitation, two-colour detection technique using anisole LIF. 

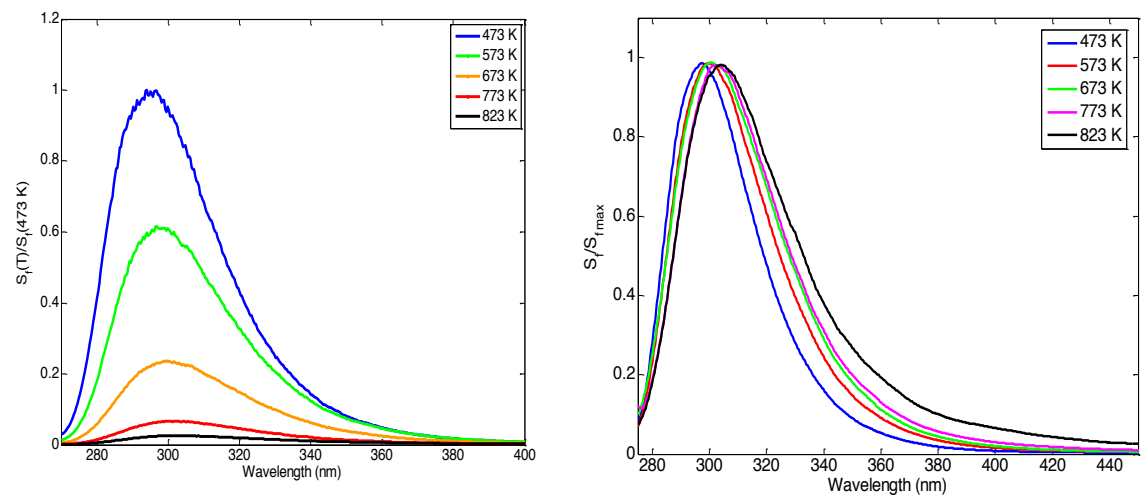

Figure 4: On the left, fluorescence spectra of anisole in carbon dioxide, at different temperatures and a constant pressure of 1.2 $\mathrm{MPa}$ (excitation wavelength: $266 \mathrm{~nm}$ ). Each spectrum is normalized by the maximum value of the fluorescence signal at $473 \mathrm{~K}$. On the right, influence of temperature on the redshift of the anisole fluorescence spectrum, in nitrogen at a pressure of 1.2 MPa. Each spectrum is normalized by the maximum value of its own fluorescence spectrum.

Figure 5 presents the combined influence of temperature and pressure on anisole fluorescence quantum yield, when it is excited at $266 \mathrm{~nm}$ in nitrogen. The fluorescence signal globally decreases continuously with increasing pressure, at a given temperature.

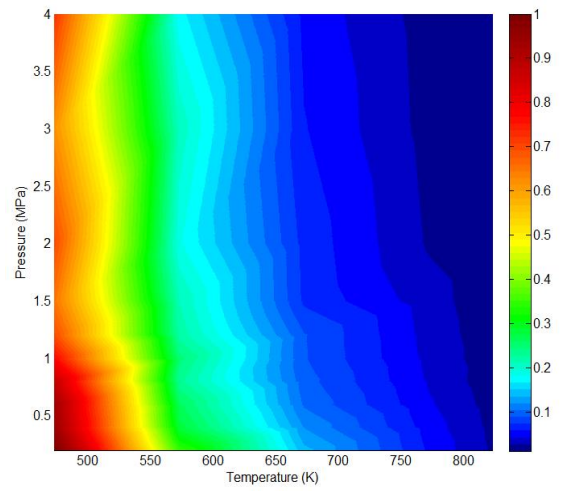

Figure 5: Map of relative fluorescence quantum yield $\Phi$ measured with anisole in nitrogen ( $\Phi$ is normalized by the reference value at $473 \mathrm{~K}$ and $0.2 \mathrm{MPa}$ )

For the case of temperature measurements made using the single-excitation, two-colour detection technique, a specific study was focused on the technique's sensitivity, as a function of the selected spectral bands $\Delta \lambda_{1}$ and $\Delta \lambda_{2}$ (cf. Eq. (3)). The aim was to select the best pair of spectral bands, in order to achieve the strongest fluorescence signal ratio and signal-to-noise ratio (SNR). For the selected spectral pair, i.e. $\Delta \lambda_{1}=374-399 \mathrm{~nm}$ and $\Delta \lambda_{2}=300-325 \mathrm{~nm}$, the fluorescence ratio increases by a factor of seven over the temperature range considered, and the SNR ratio of the integration spectral band $\Delta \lambda_{1}$ is 2.33 [23]. The best commercial bandpass filters matching these values are centred at $292 \mathrm{~nm}$, with a spectral width of $27 \mathrm{~nm}$, and at $386 \mathrm{~nm}$, with a spectral width of $23 \mathrm{~nm}$, respectively. These filters were used in the optical collection system, for PLIF temperature measurements in the RCM (cf. Figure 1). As shown in Figure 6, the fluorescence signal ratio in nitrogen increases over the range of temperature studied, by factors of 11.4 and 15 , at 0.2 and $4 \mathrm{MPa}$, respectively. The anisole emission spectrum is integrated over both spectral bands corresponding to the chosen bandpass filters. The ratio of these signals is normalized by the reference value at $473 \mathrm{~K}$, for each value of pressure. 

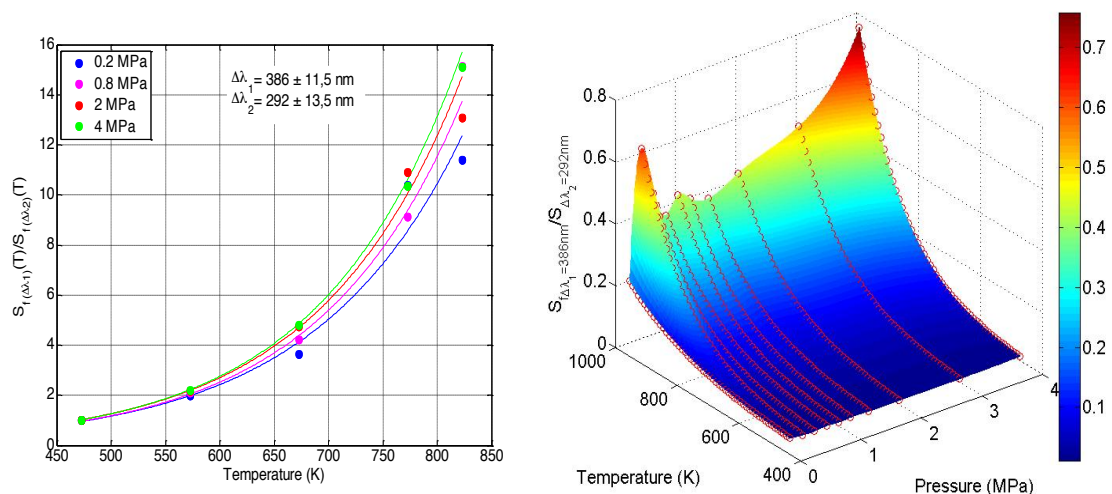

Figure 6: (a) Variation of fluorescence signal ratios in nitrogen, as a function of temperature, for different values of pressure, corresponding to two spectral bands $\left(\Delta \lambda_{1}=386 \pm 11.5 \mathrm{~nm}\right.$ and $\Delta \lambda_{2}=$ $292 \pm 13.5 \mathrm{~nm}$ ). (b) Fluorescence signal ratio calibration matrix $v s$. pressure and temperature.

The experimental fluorescence signal ratio correlations, inferred from measurements performed in three different bath gases $\left(\mathrm{N}_{2}, \mathrm{CO}_{2}, \mathrm{Ar}\right)$, are reported in Table 2. Due to the shape of the ratio as a function of temperature (see Fig.6(a)), the ratio is expected to be driven by the following phenomenological trend:

$\mathrm{S}_{\mathrm{f}}{ }^{*}=\mathrm{A}(\mathrm{P}) \exp (\mathrm{B}(\mathrm{P}) \mathrm{T})$

Considering the smooth evolution of the fluorescence signal ratio with temperature at any pressure (see Figure 6 (b)), the above expression is expected to deliver fair evaluations of the ratio for any set of temperature and pressure within the range of calibrating data without any further uncertainties. Above $900 \mathrm{~K}$, the calibration procedure could not be conducted as the HT-HP chamber starts being damaged under thermal effect above this temperature. However, the extrapolation following Eq.() is also believed to be acceptable provided that the temperature measured does not exceed the anisole pyrolysis one. This pyrolysis temperature is estimated at about $1000 \mathrm{~K}$ in the HT-HP conditions, i.e. at long and static residence time of anisole. Indeed, Faust et al. [20] observed that at temperatures beyond $1000 \mathrm{~K}$ significant pyrolysis may occur due to long residence time of the gas mixture in the vicinity of the heated walls.

When the experimental $(\mathrm{P}, \mathrm{T})$ calibration data is processed to deliver the matrix, in which the Zaxis corresponds to the fluorescence ratio, it is then possible to determine the interpolated value of the fluorescence signal ratio at each mesh node of a PLIF image obtained in the RCM.

\begin{tabular}{|c|c|c|c|}
\hline $\begin{array}{c}\mathrm{P} \\
(\mathrm{MPa})\end{array}$ & $\mathrm{N}_{2}$ & $\mathrm{CO}_{2}$ & $\mathrm{Ar}$ \\
\hline 0.2 & $S_{f}^{*}=0.0304 \exp (0.0073 T)$ & $S_{f}^{*}=0.042 \exp (0.0067 T)$ & $S_{f}^{*}=0.0523 \exp (0.0061 T)$ \\
& $\mathrm{R}^{2}=0.98$ & $\mathrm{R}^{2}=0.98$ & $\mathrm{R}^{2}=0.98$ \\
\hline 0.8 & $S_{f}^{*}=0.0264 \exp (0.0076 T)$ & $S_{f}^{*}=0.0318 \exp (0.0072 T)$ & $S_{f}^{*}=0.045 \exp (0.0063 T)$ \\
& $\mathrm{R}^{2}=0.99$ & $\mathrm{R}^{2}=0.99$ & $\mathrm{R}^{2}=0.99$ \\
\hline 2 & $S_{f}^{*}=0.0283 \exp (0.0076 T)$ & $S_{f}^{*}=0.036 \exp (0.0068 T)$ & $S_{f}^{*}=0.0316 \exp (0.0071 T)$ \\
& $\mathrm{R}^{2}=0.99$ & $\mathrm{R}^{2}=0.98$ & $\mathrm{R}^{2}=0.99$ \\
\hline 4 & $S_{f}^{*}=0.0256 \exp (0.0076 T)$ & $S_{f}^{*}=0.0313 \exp (0.0072 T)$ & $S_{f}^{*}=0.0216 \exp (0.0077 T)$ \\
& $\mathrm{R}^{2}=1$ & $\mathrm{R}^{2}=0.98$ & $\mathrm{R}^{2}=0.97$ \\
\hline
\end{tabular}

Table 2: Experimental fluorescence signal ratio correlations: $S_{f}^{*}=\frac{S_{f}^{\Delta \lambda_{1}}(T, P)}{S_{f}^{\Delta \lambda_{2}}(T, P)}=f(T)$ for anisole, at different pressures and using different bath gases. The chosen spectral bands are $\Delta \lambda_{1}=386 \pm 11.5$ $\mathrm{nm}$ and $\Delta \lambda_{2}=292 \pm 13.5 \mathrm{~nm}$. 
The uncertainty in the RCM temperature measurement is estimated to lie between $6.8 \%$ and $8.9 \%$ for the explored range of temperature and pressure, i.e., 473-823 $\mathrm{K}$ and $0.2-4 \mathrm{MPa}$. This uncertainty takes into account the errors in the HP-HT cell calibration measurements, as well as the RCM pressure measurements.

The parameter range over which this methodology can be applied is constrained by several phenomena. First, even if the spectral signal ratio has a significant value, the temperaturedependent fluorescence SNR must be sufficiently high. We arbitrarily set the detection limit at an SNR equal to 1.1 for the $386 \mathrm{~nm}$ filter, and 2.0 for the $292 \mathrm{~nm}$ filter.

Another limitation is related to the anisole pyrolysis. In order to check that no anisole pyrolysis or photo-physical decomposition occurred during the experiments (especially at high temperatures), the anisole fluorescence spectrum was measured between $473 \mathrm{~K}$ and $823 \mathrm{~K}$, over a long period of time. The magnitude and shape of the anisole fluorescence spectrum changed after approximately 10 minutes at the lowest temperature, and approximately 8 minutes at the highest temperature. The experimental process, starting with injection of the solution, and ending with the acquisition of data, does not exceed $3 \mathrm{~min}$. Over this period of time, any change in the anisole fluorescence spectrum would have been observed. It can thus be concluded that there was no degradation of the anisole during the experiments. Further detailed discussion about the anisole thermal decomposition and its initial pyrolysis can be found in [24], [25].

\subsection{Temperature distributions inside the RCM}

Using the image processing steps, thermal fields were computed at different times between TDC and $40 \mathrm{~ms}$ after TDC, under different experimental conditions (cf. Table 1). Figure 7 shows the temperature maps and the associated histograms computed at TDC, TDC $+10 \mathrm{~ms}$, and TDC +30 ms. The inert mixture is here equivalent to the n-heptane reactive mixture (see case 1 in Table 1).
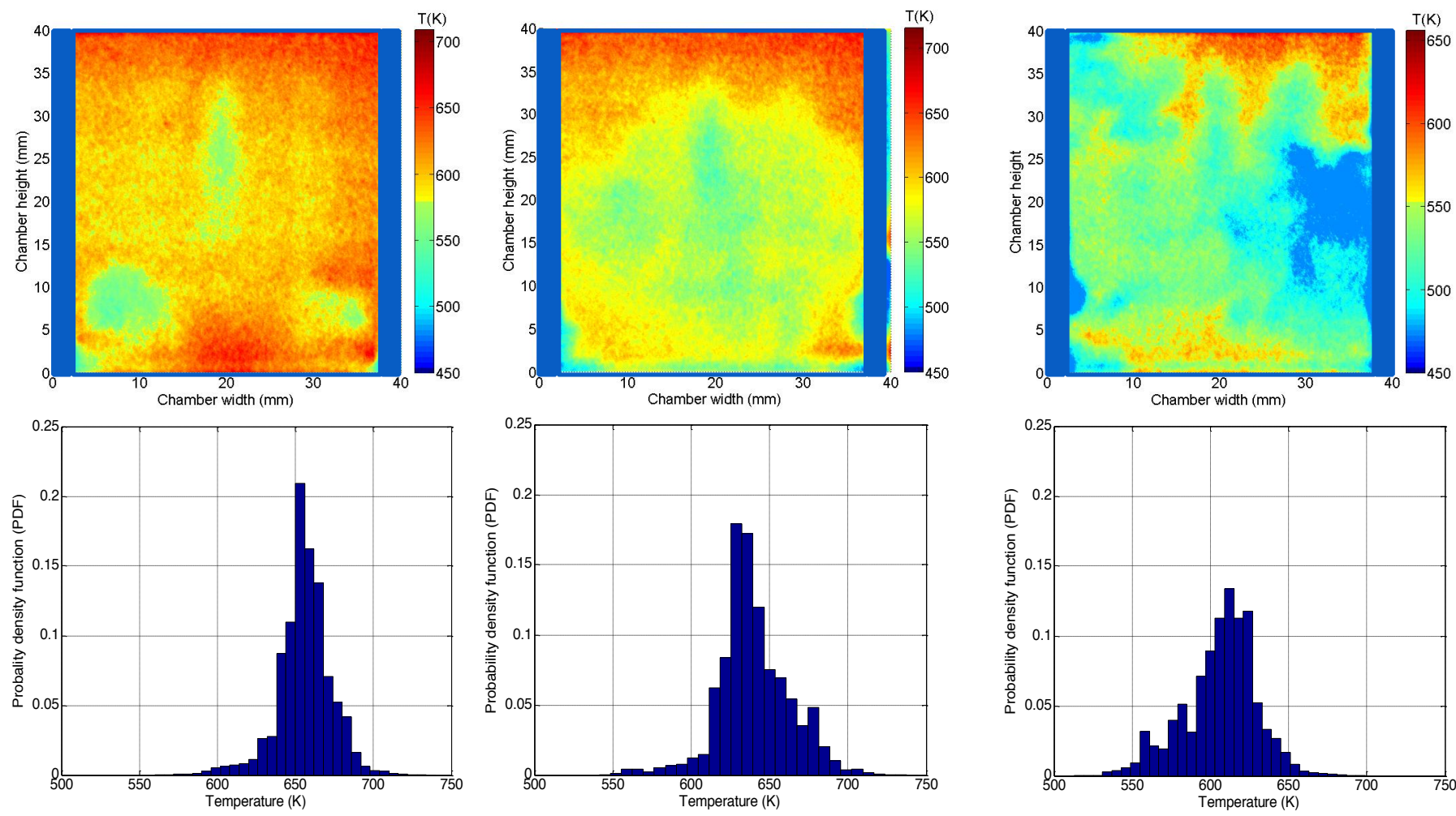

TDC 
Figure 7: Temperature fields, profiles and histograms at different times after the end of compression: (a) TDC, (b) TDC $+10 \mathrm{~ms}$, (c) TDC $+30 \mathrm{~ms}$. The inert mixture is here equivalent to the n-heptane reactive mixture (charge of $180 \mathrm{~mol} / \mathrm{m}^{3}$ and equivalence ratio of 0.8 as reported in Table 1). The adiabatic temperature computed by the $0 \mathrm{D}$ model at $\mathrm{TDC}$ is $\mathrm{T}_{\text {cal }}=667 \mathrm{~K}$.

The temperature fields can be seen to be inhomogeneous. At TDC, the hot zones (approximately $685 \mathrm{~K}$ ) are located at the top of the chamber, and cool zones close to the walls exhibit temperatures ranged between 615 and $630 \mathrm{~K}$. The kernels of the vortices located in both lower corners (see the velocity fields in Figure 10) can be observed, exhibiting temperatures ranging between 615 and $630 \mathrm{~K}$. After TDC, the cold zones spread over from the lateral walls and from the bottom of the cylinder, amplifying the temperature heterogeneities. When the cold zones are conveyed towards the centre of the chamber, finger-like thermal heterogeneities propagate from the wall towards the centre. The temperature histograms also reflect these thermal heterogeneities. Over time, the probability density function (pdf) broadens and shifts towards lower temperatures.

Moreover, the pdf peak at TDC is centred at $653 \mathrm{~K}$. This is in agreement with the adiabatic temperature of $667 \mathrm{~K}$ calculated with the $0 \mathrm{D}$ multi-zone model that accounts for heat and mass transfer among RCM zones.

In Figure 8, the temperature field measurements correspond to an inert mixture that is equivalent to that of iso-octane (case 2, charge of $160 \mathrm{~mol} / \mathrm{m}^{3}$ and equivalence ratio of 0.6 ). It is important to note that the auto-ignition process is always initiated at the top of the combustion chamber, approximately $22 \mathrm{~ms}$ after TDC. Figure 8 shows that in this area the temperature field is nearly heterogeneous. This involves specific propagation of the combustion front, which depends on the local temperature gradient.
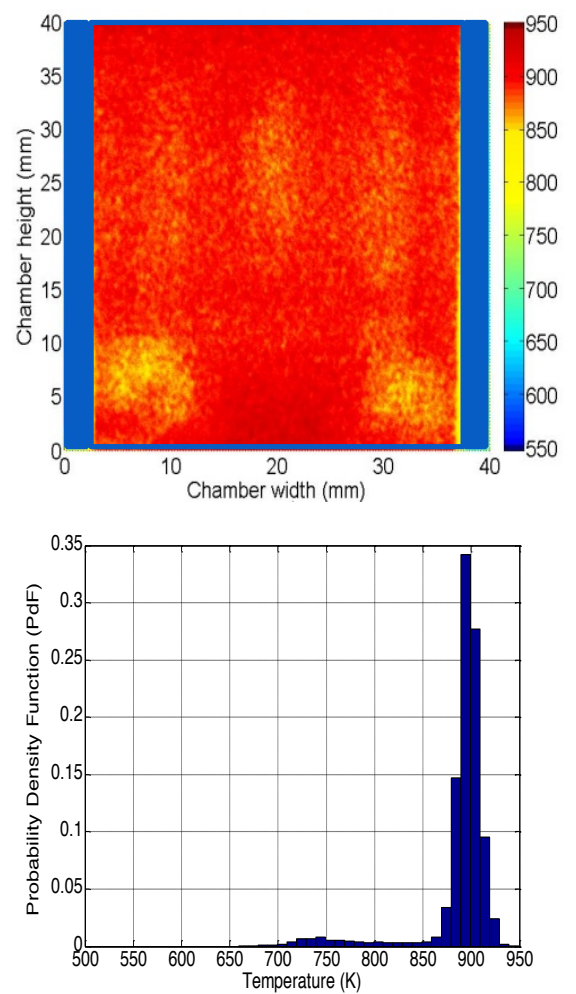

TDC

(a)
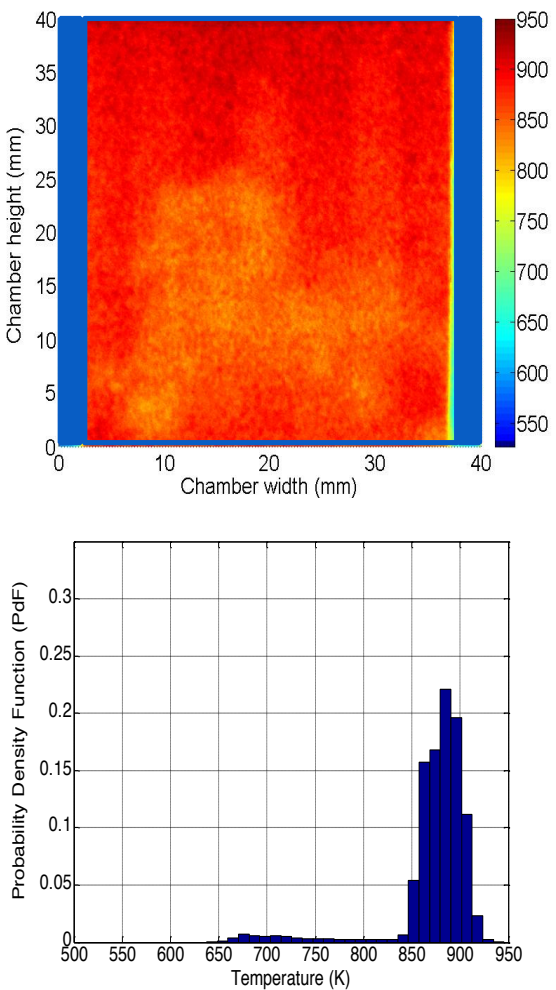

$\mathrm{TDC}+10 \mathrm{~ms}$

(b)
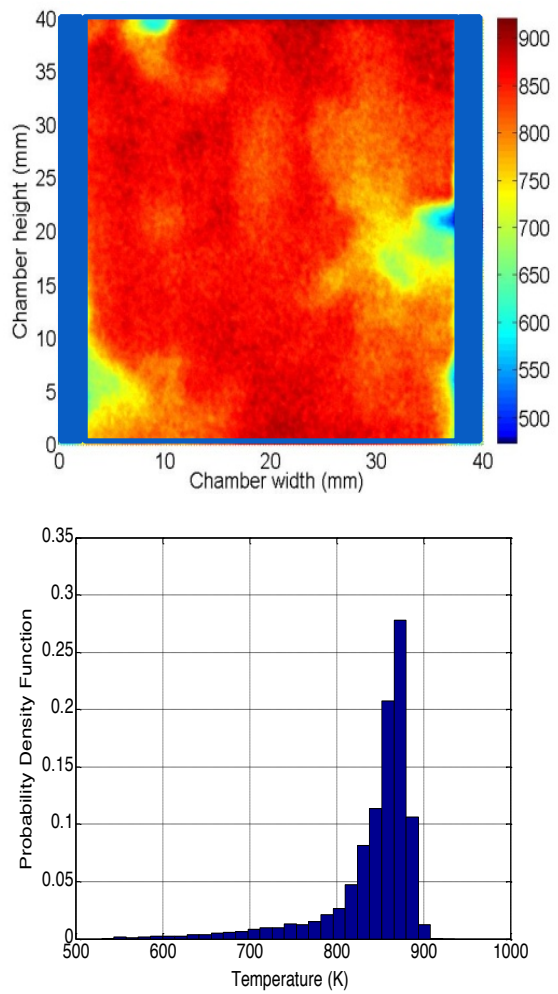

$\mathrm{TDC}+30 \mathrm{~ms}$

(c) 
Figure 8: Temperature fields and histograms at different times after the end of compression: (a) TDC, (b) TDC $+10 \mathrm{~ms}$, (c) TDC $+30 \mathrm{~ms}$, The inert mixture is here equivalent to the iso-octane reactive mixture (charge of $160 \mathrm{~mol} / \mathrm{m}^{3}$ and equivalence ratio of 0.6 as reported in Table 1). The adiabatic temperature computed by the $0 \mathrm{D}$ model at $\mathrm{TDC}$ is $\mathrm{T}_{\text {cal }}=884 \mathrm{~K}$.

The last experimental configuration, shown in Figure 9, corresponds to an inert mixture equivalent to a reactive hydrogen mixture (case3: charge of $160 \mathrm{~mol} / \mathrm{m}^{3}$ and equivalence ratio of 0.4 ). This condition corresponds to hydrogen auto-ignition $10 \mathrm{~ms}$ after TDC. The temperature fields and histograms are again represented at different times after TDC. Similar variations can be observed in the temperature field. The temporal evolution in temperature is also similar, with the cool zones propagating from the bottom to the top, and from the walls to the centre of the chamber. At TDC, the temperature field is highly homogeneous, two cooler kernels also appearing in the lower corners. At this time, the temperature distribution is very tight. The mean temperature then decreases with time due to the global cooling that is driven by the heat loss at the walls. This local heat transfer naturally leads to enhanced thermal heterogeneities.

The TDC temperature histograms shown in Figure 8 and Figure 9 exhibit probability density function peaks of 0.34 and 0.38 , centred at $894 \mathrm{~K}$ and $927 \mathrm{~K}$, respectively. These temperature levels are in agreement with the adiabatic temperatures of $884 \mathrm{~K}$ and $926 \mathrm{~K}$, respectively, calculated with the $0 \mathrm{D}$ model. The asymmetric feature of the distributions increases with time as a result of the predominant cooling processes at the cold walls of the combustion chamber.
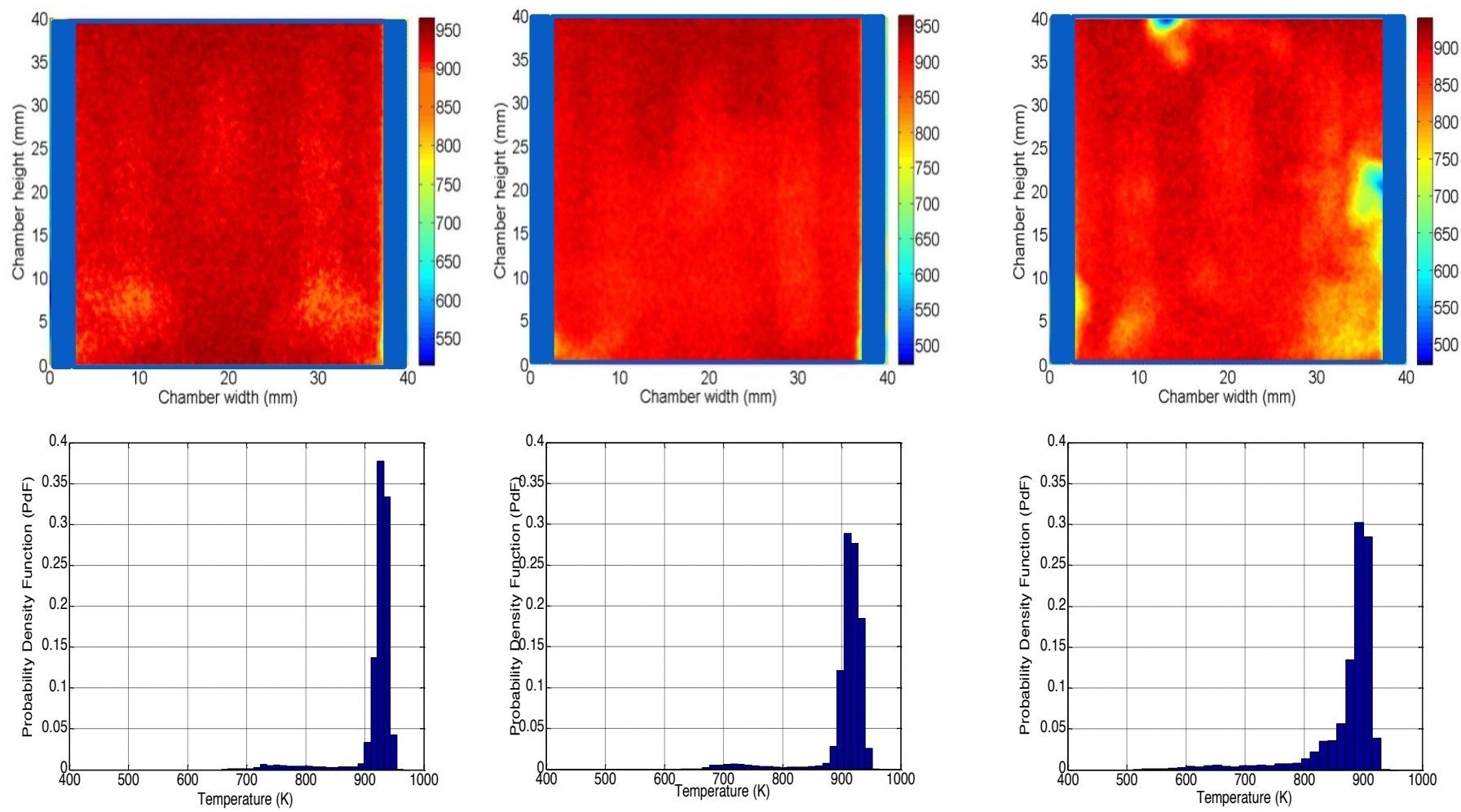

TDC

$\mathrm{TDC}+10 \mathrm{~ms}$

(a)

(b)

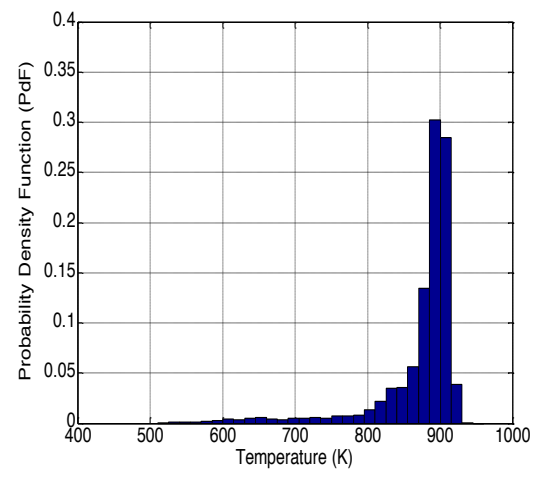

$\mathrm{TDC}+30 \mathrm{~ms}$

(c)

Figure 9: Temperature fields and histograms at different times after the end of compression: (a) TDC, (b) TDC $+10 \mathrm{~ms}$, (c) TDC $+30 \mathrm{~ms}$. The inert mixture is here equivalent to the $\mathrm{H}_{2}$ reactive mixture (charge of $160 \mathrm{~mol} / \mathrm{m}^{3}$ and equivalence ratio of 0.4 as reported in Table 1 ). The adiabatic temperature computed by the $0 \mathrm{D}$ model at $\mathrm{TDC}$ is $\mathrm{T}_{\text {cal }}=926 \mathrm{~K}$.

The analysis of the spatio-temporal fluctuations of the temperature field is an important step towards the deep understanding of the auto-ignition phenomenon and the subsequent combustion processes. This is especially a key point when it comes to the identification of the actual 
discrepancies among different RCMs. Discriminating these discrepancies is ultimately crucial to the fair interpretation of the ignition delays.

Under the various experimental conditions described here, we observe a highly non-uniform temperature field following the end of compression, characterised by two cold cores, which may affect the combustion process. In order to gain a better understanding of the temperature distribution inside the RCM, we focus on the interaction between gas flow induced by the inner geometry of the RCM, and piston motion. Velocity fields were measured by Particle Image Velocimetry (PIV). Following a similar setup as the one outlined in [19], the PIV diagnostics was performed in the RCM. The laser sheet was generated by a pulsed $(10 \mathrm{~Hz}) \mathrm{Nd}$ :Yag laser. A CCD camera equipped with a $60 \mathrm{~mm}$ lens was aligned perpendicular to the laser sheet to image the light scattered by the seeding particles. Micrometric, liquid Rhodorsil particles were used to seed the gas flow. PIV measurements were performed for an inert mixture equivalent to the n-heptane reactive mixture (charge of $180 \mathrm{~mol} / \mathrm{m}^{3}$ and equivalence ratio of 0.8 ). A pulse generator allowed the laser pulse to trigger the exposure of the frames.

Figure 10 shows the temperature fields measured using LIF together with the velocity fields measured using PIV, at different times following the end of compression, i.e., TDC, TDC $+10 \mathrm{~ms}$, $\mathrm{TDC}+17 \mathrm{~ms}$, and TDC $+25 \mathrm{~ms}$. Although the LIF and PIV measurements were not made simultaneously, the RCM acquisition system enables the sharp triggering of these measurements. Therefore both temperature and velocity measurements were conducted under identical experimental conditions. The maps presented in the following are averaged velocity fields, determined from 10 successive, instantaneous tests.

At TDC, two vortices can be observed close to the walls in the lower corners. The velocity measured in the vortices ranges between 10 and $22 \mathrm{~m} / \mathrm{s}$. Both eddies grow and are conveyed due to the upward axial jet expelled after the piston stopped. The eddies then collide with the top end $25 \mathrm{~ms}$ after the end of compression. The global flow feature decreases rapidly, as a result of the unsteady flow. Comparing the evolution with time of the velocity and temperature fields, a strong correlation appears between the thermal and aerodynamic phenomena in the combustion chamber. Indeed, the locations of the vortices observed at TDC match those of the thermal kernels. As outlined by Guibert et al. [19], these vortices are formed due to gas pinching between the bottom of the cylinder and the piston head. These vortices convey cool gases from the walls towards the centre of the combustion chamber. The eddies then grow and propagate towards the upper combustion chamber, leading to cooling at the centre of the chamber. This aero-thermal interaction is well defined between 10 and $17 \mathrm{~ms}$. When the eddies collapse due to the collision with the top end, cooling of the hottest area occurs $25 \mathrm{~ms}$ after the end of compression. At this time, it can be seen that some heat is transferred from the walls towards the centre of the chamber.

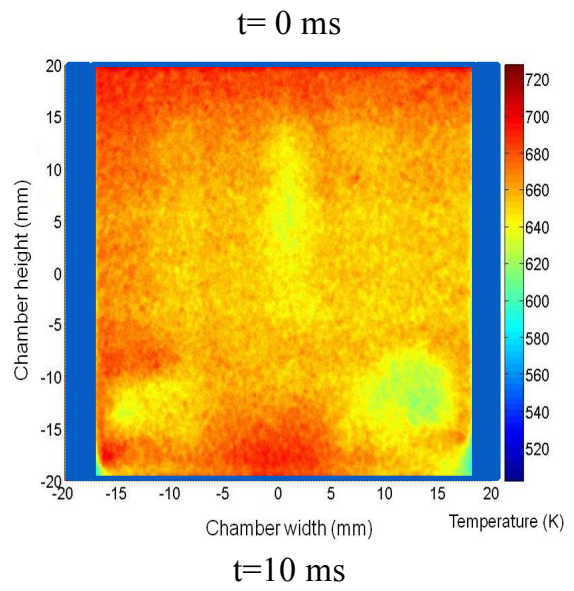

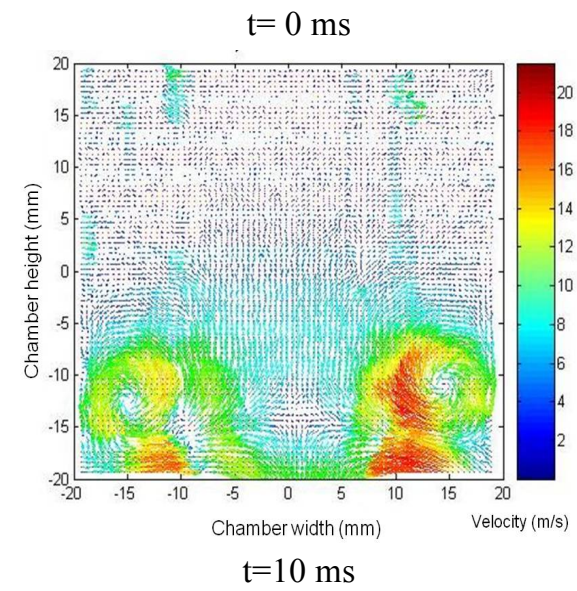



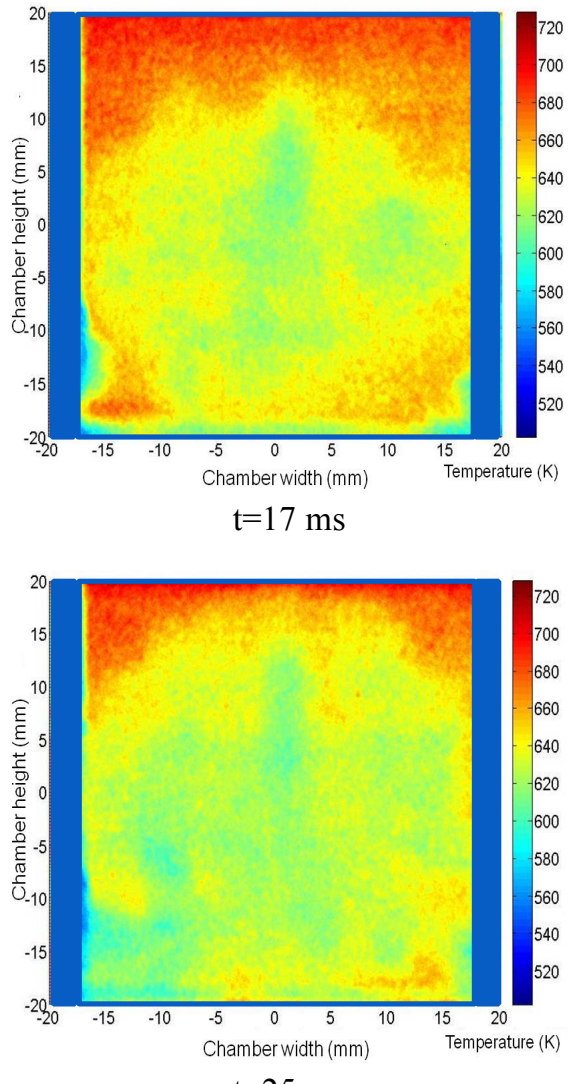

$\mathrm{t}=25 \mathrm{~ms}$

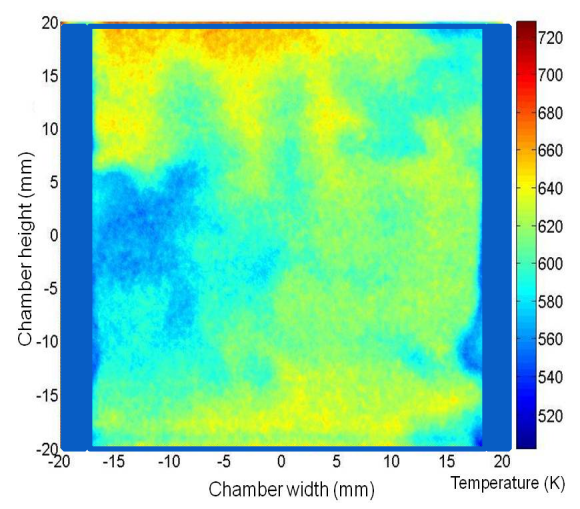

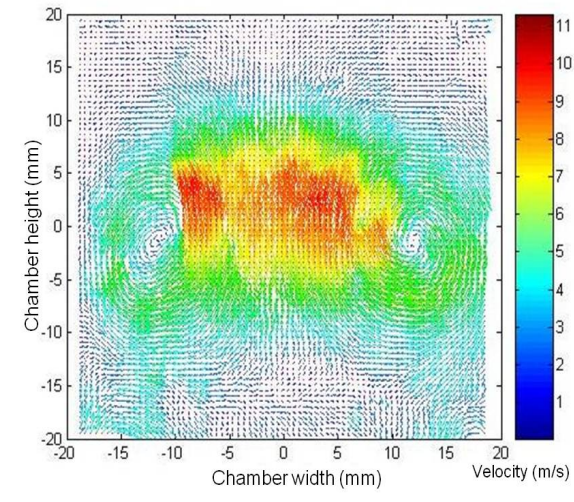

$\mathrm{t}=17 \mathrm{~ms}$

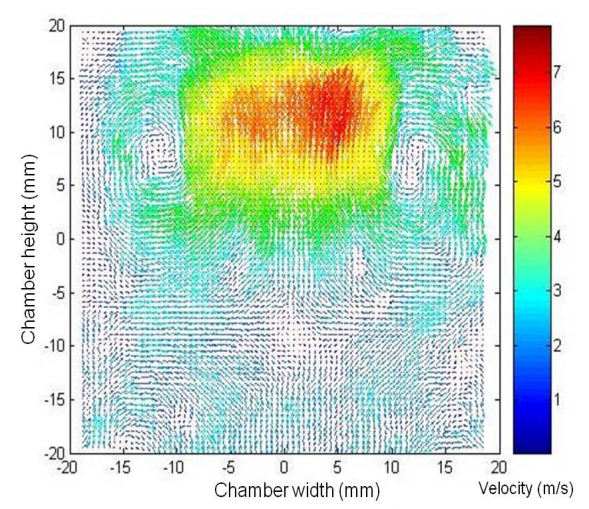

$\mathrm{t}=25 \mathrm{~ms}$

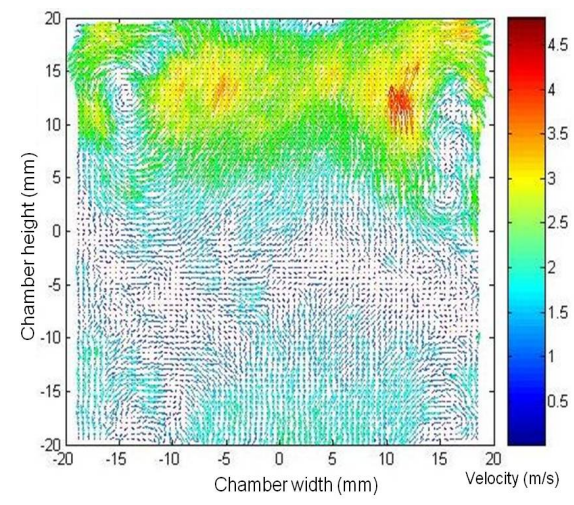

Figure 10: Temperature and velocity fields at different times after TDC. The inert mixture is here equivalent to the $\mathrm{n}$-heptane reactive mixture (charge of $180 \mathrm{~mol} / \mathrm{m}^{3}$ and equivalence ratio of 0.8 ).

The temperature distribution at TDC is especially influenced by the geometry of the RCM and the piston motion during the compression stroke. Indeed, while the piston is rising, gas is transferred from the compression chamber towards the smaller combustion chamber. With the ensuing increase in pressure, the gas temperature increases rapidly and homogenously until TDC. Then, due to the geometry of the piston head and the bottom of the cylinder, two aerodynamic vortices are formed due to gas pinching, as shown in Figure 11. The vortices are cooler than the bulk gas, as a consequence of the high surface to volume ratio of the pinched gas, which is cooled by convective heat transfer from the piston head and the wall at the bottom of the cylinder.

$$
\mathrm{t}<<\mathrm{t}_{\mathrm{TDC}} \quad \mathrm{t}<\mathrm{t}_{\mathrm{TDC}} \quad \mathrm{t}=\mathrm{t}_{\mathrm{TDC}}
$$




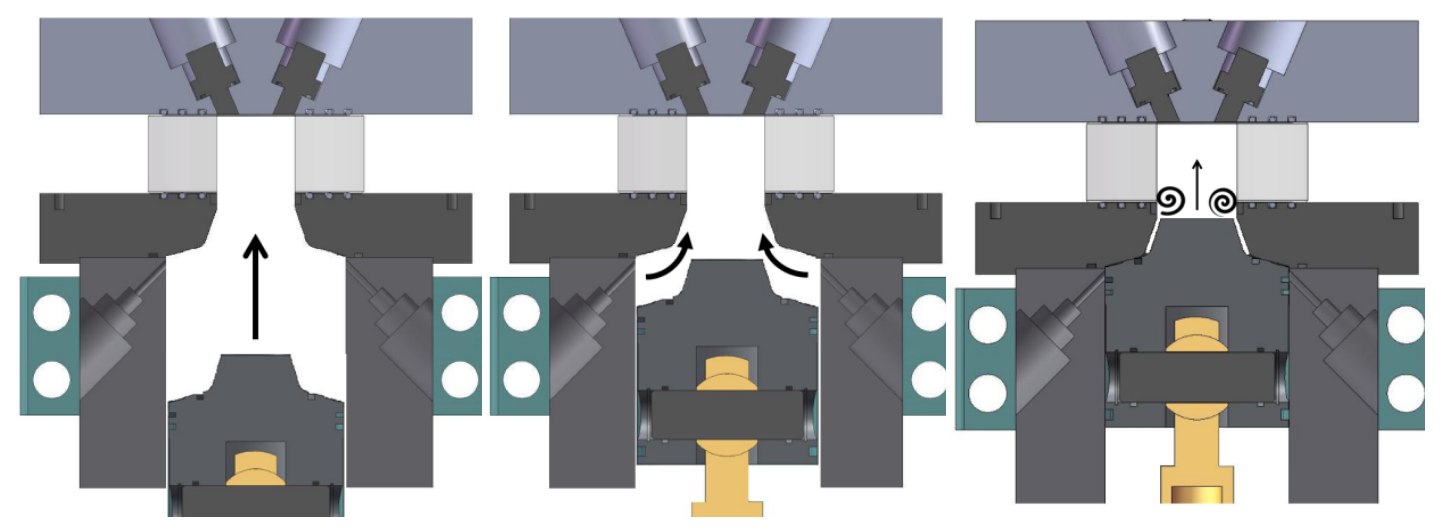

Figure 11: Cross-section of the inner RCM geometry. The arrows represent the gas flow at successive times until the end of compression.

Several authors have evidenced the temperature heterogeneities that exist in an RCM. Clarkson et al. [3] also observed the presence of a roll-up vortex that collects cool gas from the walls and moves this gas across the cylinder head, pushing it forward into a plug at the centre. They also described a spatially non-uniform temperature field after compression, with a cold core affecting the potential chemical runaway in the combustion chamber. Recently, Mittal and Sung [4] used acetone PLIF to investigate the effects of aerodynamics on the measured properties inside an RCM. Their experiments especially highlighted the discrepancies associated with the use of a flat piston and a creviced one, under varying conditions. In agreement with the present study, Mittal and Sung observed that the flat piston design leads to significant mixing of the cold vortex with the hot core region, thereby promoting the coexistence of hot and cold regions inside the combustion chamber.

\section{Conclusion}

We presented a methodology based on the use of PLIF, to achieve quantitative temperature measurements in an RCM. This involves the development of calibration measurements in a HPHT cell and image processing, depending on the experimental conditions used in the RCM. As a result of its spectroscopic characteristics and temperature sensitivity, anisole is shown to be an appropriate tracer for temperature measurements, based on the single excitation, two-colour detection technique. From the experiments carried out with an HP-HT cell, calibration fits were obtained over a large range of temperatures and pressures, i.e., $473-823 \mathrm{~K}$ and $0.2-4 \mathrm{MPa}$, respectively, and for three different gases, i.e., nitrogen, carbon dioxide, and argon.

The temperature fields were inferred from the fluorescence images through the application of a correction and calibration procedure. An approach allowing quantitative measurements to be obtained was developed in this study. This is based on the normalization of images with respect to the laser energy, and corrections for the background contribution and the variations in the laser beam profile. The final image processing step consists in applying calibration fits. At different times after the end of the compression, temperature fields were measured for different inert mixtures whose compositions are adjusted to generate thermo-physical characteristics that are equivalent to those of reactive n-heptane, iso-octane, and hydrogen mixtures. The temperature field was found to be non-uniform. Hot and cold areas appeared as a result of recirculation in the chamber, convective heat transfer from the walls during compression and after TDC, compression of core gas, and flow motion towards the top end of the combustion chamber. Velocity fields were measured using PIV, in order to characterize the influence of gas flow on the spatial distribution of temperature. The comparison between velocity and temperature fields at identical times reveals a strong correlation between thermal and aerodynamic phenomena in the combustion chamber. As 
highlighted in the literature, the variations in eddy structure and residual turbulence levels drive a combustion phenomenology depending mainly on two major parameters, i.e., local turbulence and the thermal gradient. Thus, the geometry of the RCM plays a first order role, influencing the conditions experienced by the mixture at the end of compression.

The main results of this study are that the PLIF technique is a highly useful tool for a large variety of practical situations, including those experienced in a confined, high pressure, high temperature combustion chamber. In the future, combustion systems will require a more detailed knowledge of thermodynamic and aerodynamic processes.

Severe conditions relevant to IC engines are considered here. The present paper clearly demonstrates the possibility of studying the evolution of thermal fields and associated temperature gradients. From the point of view of kinetics-related combustion this experimental characterization can bring useful information for the interpretation of RCM auto-ignition data. These observations could especially help explain the experimental discrepancies among the ignition delays measured in different RCMs, especially for mixtures exhibiting fairly short ignition delays. Heterogeneity (thermal and gas composition) together with turbulence play a significant role in the balance between auto-ignition process, front-like propagation, and potential transition to detonation.

\section{Acknowledgements}

This study was performed during the PhD thesis of K.H. Tran, and was supported by the FUI (French Fond Unique Interministériel) in the framework of the MODELESSAIS Pôles de Compétitivité MOVE'O project.

\section{References}

[1] R. Minetti, M. Carlier, M. Ribaucour, E. Therssen et L. Sochet, A rapid compression machine investigation of oxidation and auto-ignition of n-heptane measurements and modelling, Combust. Flame, 102 (1995) 298-309.

[2] M. Donovan, X. He, B. Zigler, T. Palmer, M. Wooldrigde et A. Atreya, Demonstration of a free-piston rapid compression facility for the study of high temperature combustion phenomena, Combust. Flame, 137 (2004) 351-365.

[3] J. Clarkson, J. Griffiths, J. Macnamara et B. Whitaker, Temperature fields during the development of combustion in a Rapid Combustion Machine, Combust. Flame, 125 (2001) 1162-1175.

[4] G. Mittal et C. Sung, Aerodynamics inside a Rapid Compression Machine, Combust. Flame, 145 (2006) 160-180.

[5] M. Thurber, F. Grisch et R. Hanson, Temperature imaging with single and dual wavelength acetone planar laser-induced fluorescence, Opt. Lett., 22 (1997) 251-253.

[6] M. Luong, R. Zhang, C. Schulz et V. Sick, Toluene laser-induced fluorescence for in-cylinder temperature imaging in internal combustion engines, Appl.Phys.B 91 (2008) 669-675.

[7] V. Modica, C. Morin et P. Guibert, 3-Pentanone LIF at elevated temperatures and pressures: measurements and modeling, Appl. Phys. B, 87 (2007) 193-204.

[8] D. Rothamer, J. Snyder, R. Hanson, R. Steeper et R. Fitzgerald, Simultaneous imaging of exhaust gas residuals and temperature during HCCI combustion., Proceedings of the Combustion Institute, 32 (2009) 2869-2876.

[9] M. Löffler, F. Beyrau et A. Leipertz, Acetone laser-induced fluorescence behavior for the simultaneous quantification of temperature and residual gas distribution in fired sparkignition engines, Appl. Optics, 49 (2010) 37-49.

[10] C. Strozzi, J. Sotton, A. Mura et M. Bellenoue, Characterization of a two-dimensional temperature field within a rapide compression machine using a toluene planar laser-induced fluorescence imaging technique, Meas. Sci. Technol., 20 (2009) 125-403.

[11] W. Koban, J. Koch, R. Hanson et C. Schulz, Absorption and fluorescence of toluene vapor at elevated temperatures, Phys. Chem. Chem. Phys, 6 (2004) 2940-2945. 
[12] S. Kaiser, M. Schild et C. Schulz, Thermal stratification in an internal combustion engine due to wall heat transfer measured by laser-induced fluorescence, Proceedings of the Combustion Institute, 34 (2013) 2911-2919.

[13] J. Yoo, D. Mitchell, D. Davidson et R. Hanson, Planar laser-induced fluorescence imaging in shock tube flows, Shock Waves, 21 (2011) 523-532.

[14] M. Cundy, P. Trunk, A. Dreizler et V. Sick, Gas-phase toluene LIF temperature imaging near surfaces at $10 \mathrm{kHz}$, Exp. Fluids, 51 (2011) 1169-1176.

[15] C. Schulz et V. Sick, Tracer-LIF diagnostics: quantitative measurements of fuel concentration, temperature and fuel/air ratio in pratical combustion systems, Progress in Energy and Combustion Science, 3 (2005) 75-121.

[16] M. Luong, W. Koban et C. Schulz, Novel strategies for imaging temperature distribution using toluene LIF, J.Phys.:Conf. Ser. 45 (2006) 133.

[17] S. Kaiser et M. Long, Quantitative planar laser-induced fluorescence of naphtalenes as fuel tracers, Proceedings of the combustion Institute, 30 (2005) 1555-1563.

[18] T. Hirasawa, T. Kaneba, Y. Kamata, K. Muraoka et Y. Nakamura, Temperature dependence of intensities of laser-induced fluorescence of ethylbenzene and naphtalene seeded in gas flow in atmospheric pressure, Journal of Visualisation, 10 (2007) 197-206.

[19] P. Guibert, A. Keromnes et G. Legros, An experimental investigation of the turbulence effect on the combustion propagation in a rapide compression machine, Flow. Turb. Comb., 84 (2010) 79-95.

[20] S. Faust, T. Dreier et C. Schulz, Photo-physical properties of anisole: temperature, pressure and bath gas composition dependence of fluorescence spectra and fluorescence lifetimes of toluene and naphtalene, Apply. Phys. B., 112 (2013) 203-213.

[21] S. Faust, G. Tea, T. Dreier et C. Schulz, Temperature, pressure and bath gas composition dependence of fluorescence spectra and fluorescence lifetimes of toluene and naphtalene, Appl. Phys. B, 110 (2013) 81-93.

[22] M. Orain, B. Baranger, B. Rossow et F. Grisch, Fluorescence spectroscopy of naphthalene at high temperatures and pressures : implications for fuel concentration measurements, Appl Phys B, 102 (2011) 163-172.

[23] K. Tran, C. Morin, M. Kühni et P. Guibert, Fluorescence spectroscopy of anisole at elevated temperatures and pressures, Appl. Phys. B, 115 (2014) 461-470.

[24] A. M. Scheer, C. Mukarakate, D. Robichaud, G. B. Ellison et M. R. Nimlos, Radical chemistry in the thermal decomposition of anisole and deuterated anisoles: an investigation of aromatic growth, J. Phys. Chem., 114 (2010) 9043.

[25] M. Pecullan, K. Brezinsky et I. Glassman, Pyrolysis and oxydation of anisole near $1000 \mathrm{~K}$, J. Phys. Chem., 101 (1997) 3305-3316. 